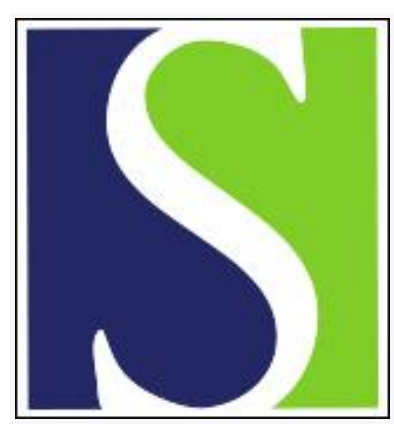

Scand J Work Environ Health 2007;33(4):272-279

https://doi.org/10.5271/sjweh.1143

Issue date: 31 Aug 2007

Symptoms and immunologic markers among vulcanization workers in rubber industries in southern Sweden

by Jönsson LS, Broberg K, Axmon A, Jönsson BAG, Littorin M

Affiliation: Division of Occupational and Environmental Medicine, University Hospital, SE-221 85 Lund, Sweden. lena_s.jonsson@med.lu.se

The following articles refer to this text: 2009;35(3):203-211;

2011;37(4):316-324

Key terms: 2-thiothiazolidine-4-carboxylic acid; airway symptom; biomarker; dose-response relationship; eye symptom; headache symptom; immunologic marker; nausea; rubber industry; Sweden; vulcanization worker

This article in PubMed: www.ncbi.nlm.nih.gov/pubmed/17717619

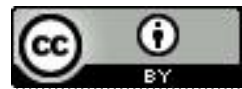




\title{
Symptoms and immunologic markers among vulcanization workers in rubber industries in southern Sweden
}

\author{
by Lena S Jönsson, PhD, ${ }^{1}$ Karin Broberg, PhD, ${ }^{1}$ Anna Axmon, PhD, ${ }^{1}$ Bo AG Jönsson PhD, ${ }^{1}$ Margareta \\ Littorin, $M D^{1}$
}

\begin{abstract}
Jönsson LS, Broberg K, Axmon A, Jönsson BAG, Littorin M. Symptoms and immunologic markers among vulcanization workers in rubber industries in southern Sweden. Scand J Work Environ Health 2007;33(4):272-279.
\end{abstract}

\begin{abstract}
Objectives The aim of this study was to estimate the risk of symptoms and the possible derangement of levels of immunologic markers for contemporary Swedish rubber workers. Furthermore, the relation between exposure and these biomarkers of response was examined using urinary levels of 2-thiothiazolidine-4-carboxylic acid (TTCA), which reflect the exposure.

Methods Included in the study were 166 exposed workers and 117 controls. Medical and occupational histories were obtained in structured interviews. Symptoms were recorded, and immunologic markers were analyzed in blood. Urinary levels of TTCA were determined by liquid chromatography tandem mass spectrometry.

Results Compared with the controls, the exposed workers had increased risks of eye symptoms [odds ratio (OR) 3.0], nose bleeds (OR 4.0), burning and dry throat (OR 3.0), hoarseness (OR 2.4), severe dry cough (OR 3.8), nausea (OR 4.3), and headache (OR 2.5). When the exposed workers were divided into three groups according to the TTCA levels, the highest risks were observed among the exposed workers with intermediate TTCA levels. Furthermore, the exposed workers in all of the TTCA subgroups had elevated concentrations of total immunoglobulin $\mathrm{G}$ when compared with the controls. Elevated concentrations of leukocytes, neutrophils, and eosinophils were observed in the group with high TTCA levels.

Conclusions This work shows an increased risk of several symptoms and elevated levels of some immunologic markers among exposed workers in Swedish rubber industries. In addition, relationships between urinary levels of TTCA and some biomarkers of response were reported.
\end{abstract}

Key terms 2-thiothiazolidine-4-carboxylic acid; airway symptom; biomarker; dose-response relationship; eye symptom; headache; nausea.

Respiratory morbidity has been associated with exposure in the rubber industry (1-4). Chronic and acute bronchitis, decreased lung function, and airway symptoms have been observed. Weeks et al $(3,5)$ and Zuskin et al (4) also surveyed other symptoms (eg, headache and nausea) among vulcanization workers. However, the environmental conditions have improved during the last few decades, and little is known about health effects in the contemporary rubber industry.

The exposure situation in the rubber industry is complex, and exposure assessments are scarce. It is, therefore, in many cases, unclear which agents cause the different symptoms. Vulcanization workers constitute a special group of rubber workers with extremely complex exposure. One way to handle the assessment of the multitudinous exposure is to use index substances (ie, a specific substance as a marker of a larger group of compounds). One such substance could be urinary 2thiothiazolidine-4-carboxylic acid (TTCA), which has traditionally been used as a marker of carbon disulfide $\left(\mathrm{CS}_{2}\right)$. Since $\mathrm{CS}_{2}$ is a compound present in fumes from sulfur vulcanization in rather high concentrations (6), urinary levels of TTCA might be used as an index substance for exposure to such rubber fumes (7).

Furthermore, urinary levels of TTCA could be interesting as a direct marker of $\mathrm{CS}_{2}$. It has been observed in vitro that $\mathrm{CS}_{2}$ can react with proteins, and urea and thiourea are likely to represent the final stable adduction products of $\mathrm{CS}_{2}$ and proteins (8). In this way, $\mathrm{CS}_{2}$ forms complexes large enough in size to evoke an immune response and thus could be an inducer of airway diseases (9). To our knowledge, only Cox et al (10), Vermeulen

1 Division of Occupational and Environmental Medicine, Department of Laboratory Medicine, Lund University Hospital, Lund, Sweden.

Correspondence to: Lena Jönsson, Division of Occupational and Environmental Medicine, University Hospital, SE-221 85 Lund, Sweden. [E-mail: lena_s.jonsson@med.lu.se] 
et al (11) and our group (7) have used TTCA to describe exposure in the rubber industry, and none of these studies addressed any kind of responses or health effects.

In this study, we characterized the risk of several symptoms, primarily for the eyes, nose, and lower airways, and the effects on the levels of different immunologic markers among contemporary vulcanization workers when compared with controls. We have also analyzed the dose-response relationships between TTCA and these outcomes.

\section{Study population and methods}

\section{Study population}

Included in the study were 166 exposed workers currently working in eight different rubber industries and 117 controls with no occupational contact with rubber or plastic chemicals, but with otherwise similar socioeconomic characteristics. All of the participants worked in southern Sweden. Some individual characteristics of the exposed workers and the controls are shown in table 1. Only the rubber workers curing with sulfur, or working in the same hall as these workers on the same day as the urine samples were collected, were selected for the study. Persons included were those who had given their informed consent and were present at work at the time of the medical examinations. Only 5.4\% (pregnancy leave taken into account) of the exposed workers had worked less than 12 months in the rubber industry. No information was available on the time they had worked with the different curing methods. Among the controls, $15.9 \%$ (pregnancy leave taken into account) had worked less than 12 months at their present workplace. A moredetailed description of the study population has been given elsewhere (7).

Complete information on the urinary levels of TTCA, symptoms, and the levels of immunologic markers were available for 146 exposed workers and 99 controls. For the remaining participants data on one or more parameters was missing, but these persons were included in the analyses when possible. The participants gave their informed written consent to take part in the study, and the study was approved by the Regional Ethical Committee of Lund University.

\section{Medical examination}

Medical and occupational histories were obtained in structured interviews, based on a slightly modified questionnaire adopted from Nielsen et al (12) and used by Littorin et al (13). The structured interviews were carried out by a physician, a trained specialist in occupational medicine. The same person performed all of the interviews, and she was aware of the exposure status at the time of the interviews. Questions dealt with symptoms that had occurred during the past 12 months and had affected the eyes (itching; running; burning), nose (bleeding; running; stuffiness; sneezing or itching), or lower airways (severe dry cough; dyspnea, wheezing, chest tightness). Furthermore, other symptoms supposedly associated with exposure to fumes (ie, throat burning, dryness; hoarseness; headache; nausea) were recorded. At the time of the medical examinations, the results of the biomarker analyses were not known to the workers or the investigators.

\section{Blood analysis}

Venous blood samples were collected during work and handled according to the instructions from the laboratories involved. Number per liter of leukocytes, neutrophils and eosinophils, plasma concentrations of $\alpha 1$-antitrypsin and C-reactive protein (CRP), total immunoglobulin (Ig) G, IgM and IgA, and the concentrations in serum of total and specific IgE against 10 common allergens (Phadiatop test by fluoroimmunoassay) were analyzed by routine clinical methods. Atopy was defined as positive when at least one of the allergens in the Phadiatop test gave a response. The blood analyses were performed on blinded samples.

\section{Analysis of urinary 2-thiothiazolidine-4-carboxylic acid}

Urine was collected both from the exposed workers and from the controls during the last 4 hours of the workshift. The samples were collected on Tuesday through Thursday. The level of TTCA was analyzed by liquid chromatography tandem mass spectrometry (LC-MSMS) as previously described (11). The limit of detection (LOD) was determined to be $1 \mathrm{ng} / \mathrm{ml}$ urine. Samples with LOD levels were assigned a value of half the LOD. The precision was $11 \%$ at $10 \mathrm{ng} / \mathrm{ml}$ and $7 \%$ at $70 \mathrm{ng} / \mathrm{ml}$.

Table 1. Characteristics of the exposed workers and the controls.

\begin{tabular}{|c|c|c|c|c|c|c|c|c|c|c|}
\hline \multirow[t]{2}{*}{ Group } & \multicolumn{2}{|c|}{ Age (years) } & \multicolumn{2}{|c|}{ Gender } & \multicolumn{2}{|c|}{ Smoking a } & \multicolumn{2}{|c|}{ Atopy } & \multicolumn{2}{|c|}{ Eastern Asian descent } \\
\hline & Median & Range & Male & Female & $\mathrm{N}$ & $\%$ & $\mathrm{~N}$ & $\%$ & $\mathrm{~N}$ & $\%$ \\
\hline Exposed workers $(\mathrm{N}=166)$ & 38 & 19-65 & 83 & 83 & 52 & 31 & 52 & 32 & 21 & 13 \\
\hline Controls $(\mathrm{N}=117)$ & 41 & $20-63$ & 57 & 60 & 44 & 38 & 31 & 27 & - & \\
\hline
\end{tabular}

a Includes smokers who stopped using tobacco less than 6 months ago. 
The results were within the tolerance limits presented in the Round Robin Inter-comparison Program (Professor Dr Med Hans Drexler, Institute and Out-Patient Clinic for Occupational, Social and Environmental Medicine, University of Erlangen-Nuremberg). The TTCA level was adjusted for creatinine content, which was analyzed enzymatically according to Mazzachi et al (14).

\section{Statistical analysis}

Analyses were performed comparing the entire group of exposed workers with the controls with respect to symptoms and immunologic markers. Moreover, the workers were trichotomized with respect to urinary TTCA levels (cut-off at 10 and $42 \mu \mathrm{mol} / \mathrm{mol}$ creatinine), and each subgroup was compared with the controls. The possible association between exposure and symptoms was estimated using odds ratios (OR) calculated with logistic regression. An analysis of variance (ANOVA) was used to estimate the differences in the levels of the immunologic markers between the exposure groups. A possible trend over the exposure categories (the three TTCA subgroups) was evaluated using the CochranArmitage test for trends of odds ratios using unadjusted data. A trend test with regard to differences in the immunologic markers was performed by including the TTCA subgroups as a continuous variable in a separate linear regression model. For all of the analyses two-sided significance was used.

A probability-probability plot suggested that the levels of the immunologic markers should be transformed (natural logarithm) before use in the models. For the transformed variables, the formula $100\left(\mathrm{e}^{\beta}-1\right)$, where $\beta$ is the effect estimate, was used to estimate the percentage increase or decrease in the average level of the immunologic marker in the evaluated group of exposed

Table 2. Level of 2-thiothiazolidine-4-carboxylic acid (TTCA) and the distribution of exposure to different vulcanization methods in a group of 157 exposed workers in the Swedish rubber industry. The cut-off for dividing the exposed workers into three equal-size groups was set at 10 and $42 \mu \mathrm{mol}$ TTCA/mol creatinine. (GM = geometric mean, LOD = limit of detection)

\begin{tabular}{|c|c|c|c|c|c|c|c|c|}
\hline \multirow{3}{*}{$\begin{array}{l}\text { Vulcanization } \\
\text { method }\end{array}$} & \multirow{3}{*}{\multicolumn{2}{|c|}{$\frac{\begin{array}{c}\text { umol TTCA/ } \\
\text { mol creatinine }\end{array}}{\text { GM a Range }^{\mathrm{a}}}$}} & \multicolumn{6}{|c|}{$\begin{array}{c}\text { TTCA } \\
\text { subgroup }\end{array}$} \\
\hline & & & \multicolumn{2}{|c|}{ Low } & \multicolumn{2}{|c|}{$\begin{array}{l}\text { Inter- } \\
\text { mediate }\end{array}$} & \multicolumn{2}{|c|}{ High } \\
\hline & & & N & $\%$ & $\mathrm{~N}$ & $\%$ & $N$ & $\%$ \\
\hline $\begin{array}{l}\text { Compression } \\
\text { and injection }\end{array}$ & & $<$ LOD-780 & 50 & 53 & 33 & 35 & 11 & 12 \\
\hline $\begin{array}{l}\text { Hot air, microwa- } \\
\text { ves \& fluid-bed }\end{array}$ & 49 & $5.3-700$ & 4 & 17 & 8 & 33 & 12 & 50 \\
\hline Salt bath & 86 & $8.0-950$ & 1 & 3 & 7 & 18 & 31 & 79 \\
\hline
\end{tabular}

a Presented in an earlier article by Jönsson et al (7). workers in comparison with the corresponding level in the control group (15).

All of the models were adjusted for atopy, age, gender, and smoking habits unless otherwise stated. Since the exposure duration showed a high correlation with age $\left(R_{S}=0.59\right)$, exposure duration was not included in any of the multivariate models. Furthermore, the analyses were carried out without adjustment.

The possible effect modification by smoking habits and atopy was estimated by analyzing the interaction between TTCA and the parameters in a separate analysis.

All of the analyses were done both with and without the participants with presumable Eastern Asian decent $(\mathrm{N}=21)$, their names being used as an indicator of ethnicity.

For all of the statistical analyses, SPSS v.13.0 (SPSS Inc, Chicago, IL, USA) was used, apart from the trend test for odds ratios when StatXact v. 6 (Cytel Software Corporation, Cambridge, MA, USA) was used.

\section{Results}

\section{Exposure}

The exposed workers used different curing methods, and the urinary TTCA levels varied between these methods (table 2). When the exposed workers were divided into three equally sized groups according to their urinary TTCA levels, the number of workers curing with each method differed between the exposure groups (table 2). The number of participants with presumable Eastern Asian decent was equally distributed between the three TTCA subgroups.

\section{Symptoms}

Compared with the controls, the exposed workers had increased risks of symptoms of the eyes (itching, running, burning) and throat (burning, dryness), as well as hoarseness and severe dry cough, during the past 12 months (table 3). An increased risk of nose bleeds (but of no other nasal symptoms) and nausea and headache was also observed. When the risk of symptoms was estimated for the three TTCA subgroups, increased risks were observed for the same symptoms as when all of the exposed workers were analyzed together (table 3). A statistically significant trend over the three TTCA subgroups was observed for nausea $(\mathrm{P}=0.002)$ and headache $(\mathrm{P}=0.020)$ (table 3).

We observed a statistically significant effect modification for smoking on the association between exposure and running nose when the exposed workers were divided into three TTCA subgroups $(\mathrm{P}=0.039)$, but not when all of the exposed workers were compared 
Table 3. Odds ratios (OR) with $95 \%$ confidence intervals (95\% CI) for symptoms during the past 12 months among all of the exposed workers and among the exposed workers with different levels of 2-thiothiazolidine-4-carboxylic acid (TTCA) (cut-off at 10 and $42 \mu \mathrm{mol} / \mathrm{mol}$ creatinine) (in a comparison with the controls).

\begin{tabular}{|c|c|c|c|c|c|c|c|c|}
\hline \multirow[t]{2}{*}{ Symptom } & \multicolumn{2}{|c|}{ All exposed } & \multicolumn{2}{|c|}{$\begin{array}{l}\text { Workers with low } \\
\text { TTCA levels }\end{array}$} & \multicolumn{2}{|c|}{$\begin{array}{l}\text { Workers with inter- } \\
\text { mediate TTCA levels }\end{array}$} & \multicolumn{2}{|c|}{$\begin{array}{l}\text { Workers with high } \\
\text { TTCA levels }\end{array}$} \\
\hline & $O R^{a, b}$ & $95 \% \mathrm{Cl}$ & $O R^{a, b}$ & $95 \% \mathrm{Cl}$ & $O R^{a, b}$ & $95 \% \mathrm{Cl}$ & $O R^{a, b}$ & $95 \% \mathrm{Cl}$ \\
\hline Itching, running or burning eyes & 3.0 & $1.7-5.2$ & 2.4 & $1.1-4.9$ & 4.0 & $1.9-8.2$ & 3.2 & $1.6-6.4$ \\
\hline Runny nose & 1.0 & $0.59-1.8$ & 0.49 & $0.21-1.2$ & 1.8 & $0.88-3.9$ & 1.1 & $0.49-2.2$ \\
\hline Nose stuffiness & 0.88 & $0.51-1.5$ & 0.65 & $0.30-1.4$ & 1.4 & $0.67-2.8$ & 0.66 & $0.31-1.4$ \\
\hline Sneezing or nose itching & 0.89 & $0.53-1.5$ & 0.72 & $0.35-1.5$ & 1.1 & $0.52-2.1$ & 0.85 & $0.43-1.7$ \\
\hline One or more of the nasal symptoms mentioned above & 1.3 & $0.81-2.2$ & 1.1 & $0.55-2.3$ & 1.9 & $0.93-3.9$ & 1.1 & $0.57-2.3$ \\
\hline Nose bleeds & 4.0 & $1.6-10$ & 3.7 & $1.2-11$ & 3.8 & $1.3-11$ & 3.4 & $1.1-10$ \\
\hline Throat burning and dryness & 3.0 & $1.6-5.5$ & 2.6 & $1.2-5.8$ & 3.8 & $1.7-8.1$ & 2.4 & $1.1-5.2$ \\
\hline Hoarseness & 2.4 & $1.1-5.0$ & 2.3 & $0.87-6.0$ & 3.0 & $1.2-7.5$ & 2.0 & $0.74-5.1$ \\
\hline Dyspnea, wheezing or chest tightness & 1.2 & $0.66-2.2$ & 1.2 & $0.53-2.6$ & 0.91 & $0.39-2.2$ & 1.3 & $0.60-2.8$ \\
\hline Severe dry cough & 3.8 & $1.9-7.7$ & 3.6 & $1.5-8.7$ & 5.1 & $2.2-12$ & 3.0 & $1.3-7.2$ \\
\hline Nausea & 4.3 & $1.6-12$ & 3.8 & $1.1-13$ & 5.8 & $1.8-19$ & 3.4 & $1.0-11$ \\
\hline Headache & 2.5 & $1.5-4.4$ & 2.2 & $1.1-4.7$ & 3.9 & $1.9-8.2$ & 1.9 & $0.92-3.9$ \\
\hline
\end{tabular}

a The effect estimates have been adjusted for age, gender, atopy, and smoking.

${ }^{\mathrm{b}}$ Boldface indicates statistically significant results $(P \geq 0.05)$

with the controls $(\mathrm{P}=0.81)$. Neither did we observe any effect modification of smoking on any other symptom. Regarding atopy, a statistically significant effect modification was observed for the association between exposure and eye symptoms $(\mathrm{P}=0.027)$, but not when the exposed workers were divided into three TTCA subgroups $(\mathrm{P}=0.23)$. No other effect modification of atopy was found.

Different curing methods were associated with different risks of the examined symptoms (table 4). The highest risks of hoarseness, severe dry cough, nausea, and headache were observed for exposed workers curing with compression or injection. Regarding some symptoms (eg, eye symptoms, nose bleeds and throat symptoms) the difference in risk was large between the exposed workers curing with different continuous curing methods (hot air, microwaves, fluid-bed versus salt bath), whereas for other symptoms (eg, runny nose, sneezing, or severe dry cough) it was small.

We observed no statistically significant effect modification of smoking for the association between curing method and symptoms. With respect to atopy, statistically significant effect modification was observed for runny nose $(\mathrm{P}=0.045)$.

\section{Immunologic markers}

Among the exposed workers with high levels of TTCA, increased concentrations of leukocytes, neutrophils, and eosinophils were observed, when the exposed workers were compared with the controls (table 5). There was also a statistically significant increase in the concentrations of total plasma IgG among all of the exposed workers together, as well as among all of the TTCA groups when the exposed workers were compared
Table 4. Odds ratios (OR) with 95\% confidence intervals (95\% Cl) for symptoms during the past 12 months among the exposed workers curing with different methods (in a comparison with the controls).

\begin{tabular}{|c|c|c|c|c|c|c|}
\hline \multirow[t]{3}{*}{ Symptom } & \multicolumn{6}{|c|}{ Curing method } \\
\hline & \multicolumn{2}{|c|}{$\begin{array}{c}\text { Compression \& } \\
\text { injection }\end{array}$} & \multicolumn{2}{|c|}{$\begin{array}{l}\text { Hot air, micro- } \\
\text { waves \& fluid-bed }\end{array}$} & \multicolumn{2}{|c|}{ Salt bath } \\
\hline & $O R^{a, b}$ & $95 \% \mathrm{Cl}$ & $\mathrm{OR}^{\mathrm{a}, \mathrm{b}}$ & $95 \% \mathrm{Cl}$ & $O R^{a, b}$ & $95 \% \mathrm{Cl}$ \\
\hline \multicolumn{7}{|l|}{ Itching, running or } \\
\hline Runny nose & 1.0 & $0.54-2.0$ & 1.1 & $0.39-3.0$ & 1.1 & $0.46-2.5$ \\
\hline Nose stuffiness & 0.82 & $0.43-1.6$ & 0.43 & $0.13-1.4$ & 1.5 & $0.68-3.3$ \\
\hline $\begin{array}{l}\text { Sneezing or nose } \\
\text { itching }\end{array}$ & 0.74 & 0 & 1. & 0 & 1.1 & 0.5 \\
\hline \multicolumn{7}{|c|}{$\begin{array}{l}\text { One or more of the } \\
\text { nasal symptoms }\end{array}$} \\
\hline entioned abc & 1.3 & $0.74-2.4$ & 1.0 & $0.40-2.5$ & 1.8 & $0.83-4.0$ \\
\hline $\begin{array}{l}\text { Nose bleeds } \\
\text { Throat burning }\end{array}$ & 3.9 & $1.4-10$ & 5.0 & $1.3-18$ & 3.9 & $1.2-12$ \\
\hline and dryne & 2.9 & $1.5-5.8$ & 2.0 & $0.67-5.7$ & 4.0 & $1.8-9.2$ \\
\hline Hoarseness & 2.7 & $1.2-6.1$ & 2.0 & $0.57-7.0$ & 2.2 & $0.76-6$ \\
\hline Dyspnea, wheezing & & & & & & \\
\hline or chest tightness & 1.1 & $0.54-2.1$ & 1.4 & $0.47-4.0$ & 1.4 & $0.60-3.5$ \\
\hline Severe dry cough & 5.2 & $2.4-11$ & 2.1 & $0.67-6.8$ & 2.6 & $0.98-6.7$ \\
\hline Nausea & 6.4 & $2.3-18$ & 1.1 & $0.12-11$ & 2.0 & $0.45-9.1$ \\
\hline Headache & 3.7 & $2.0-6.8$ & 2.3 & $0.90-6.0$ & 1.2 & $0.53-2.7$ \\
\hline
\end{tabular}

a The effect estimates have been adjusted for age, gender, atopy, and smoking.

with the controls (table 5). The highest concentration was observed among the exposed workers with low TTCA levels. Furthermore, increased levels of total IgE were observed in all of the TTCA subgroups, but the difference did not reach statistical significance. A statistically significant trend over the TTCA subgroups was observed for leukocytes $(\mathrm{P}=0.017)$ (table 5).

We observed no statistically significant effect modification of smoking for the association between exposure 
Table 5. Changes ${ }^{\text {a }}$ with $95 \%$ confidence intervals $(95 \% \mathrm{CI})$, in the levels of immunologic markers among all of the exposed workers and exposed workers with different levels of 2-thiothiazolidine-4-carboxylic acid (TTCA) exposure (cut-off at 10 and $42 \mu \mathrm{mol} / \mathrm{mol} \mathrm{creatinine}$ ) (in a comparison with the controls). ( $\mathrm{lg}=$ immunoglobulin)

\begin{tabular}{|c|c|c|c|c|c|c|c|c|}
\hline \multirow[t]{2}{*}{ Marker } & \multicolumn{2}{|c|}{ All exposed } & \multicolumn{2}{|c|}{$\begin{array}{l}\text { Workers with low } \\
\text { TTCA levels }\end{array}$} & \multicolumn{2}{|c|}{$\begin{array}{l}\text { Workers with inter- } \\
\text { mediate TTCA levels }\end{array}$} & \multicolumn{2}{|c|}{$\begin{array}{l}\text { Workers with high } \\
\text { TTCA levels }\end{array}$} \\
\hline & Change $^{a, b, c}$ & $95 \% \mathrm{Cl}$ & Change ${ }^{a, b, c}$ & $95 \% \mathrm{Cl}$ & Change ${ }^{a, b, c}$ & $95 \% \mathrm{Cl}$ & Change $^{a, b, c}$ & $95 \% \mathrm{Cl}$ \\
\hline Leukocytes & 3.8 & $-2.3-10$ & 0.0 & $-8.1-8.7$ & -1.8 & $-9.5-6.5$ & 12 & $-3.0-21$ \\
\hline Neutrophils & 4.1 & $-3.8-13$ & 1.3 & $-9.2-13$ & -2.1 & $-12-9.0$ & 12 & $0.50-24$ \\
\hline Eosinophils & 13 & $-0.60-28$ & 3.8 & $-13-24$ & 1.5 & $-14-20$ & 26 & $6.3-49$ \\
\hline$\alpha 1$-antitrypsin & 1.1 & $-2.6-5.0$ & 2.3 & $-2.9-7.8$ & 0.10 & $-4.9-5.3$ & 1.4 & $-3.5-6.6$ \\
\hline C-reactive protein & 1.5 & $-6.1-9.7$ & 4.2 & $-6.4-16$ & -0.80 & $-11-10$ & 0.0 & $-9.9-11$ \\
\hline $\lg G$ & 12 & $5.2-16$ & 14 & $6.4-22$ & 9.7 & $2.5-17$ & 8.2 & $1.2-16$ \\
\hline $\lg A$ & -4.4 & $-13-5.5$ & -4.8 & $-17-9.4$ & -3.3 & $-16-11$ & -11 & $-22-2.0$ \\
\hline $\lg M$ & 5.0 & $-5.4-17$ & 9.1 & $-5.7-26$ & 1.2 & $-12-17$ & 0.40 & $-13-16$ \\
\hline $\lg \mathrm{E}$ & 29 & $-2.5-70$ & 43 & $-2.2-110$ & 14 & $-22-65$ & 35 & $-6.9-95$ \\
\hline
\end{tabular}

a Percentage of change in the average value of the outcome in each examined group compared with the corresponding value of the controls.

${ }^{\mathrm{b}}$ Adjusted for age, gender, atopy and smoking.

c Boldface indicates statistically significant results $(P \geq 0.05)$.

Table 6. Changes with $95 \%$ confidence intervals $(95 \% \mathrm{Cl})$, in the levels of immunologic markers among the exposed workers curing with different methods (in a comparison with the controls). (C = change, $\mathrm{Ig}=$ immunoglobulin)

\begin{tabular}{|c|c|c|c|c|c|}
\hline \multirow[t]{3}{*}{ Marker } & \multicolumn{5}{|c|}{ Curing method } \\
\hline & \multicolumn{2}{|c|}{$\begin{array}{c}\text { Compression \& } \\
\text { interjection }\end{array}$} & $\begin{array}{l}\text { Hot air, micro- } \\
\text { waves, fluid-bed }\end{array}$ & \multicolumn{2}{|c|}{ Salt bath } \\
\hline & $\mathrm{C}^{\mathrm{a}, \mathrm{b}, \mathrm{c}}$ & $95 \% \mathrm{Cl}$ & $\mathrm{C}^{\mathrm{a}, \mathrm{b}, \mathrm{c}} \quad 95 \% \mathrm{Cl}$ & $C^{a, b}$ & $95 \% \mathrm{Cl}$ \\
\hline Leukocytes & 3.3 & $-3.9-11$ & $6.7-4.7-19$ & 5.4 & $-3.7-15$ \\
\hline Neutrophils & 4.0 & $-5.2-14$ & $4.9-9.1-21$ & 5.3 & $-6.5-19$ \\
\hline Eosinophils & 9.5 & $-5.4-27$ & $25 \quad-0.80-57$ & 12 & $-7.4-36$ \\
\hline$\alpha 1$-antitrypsin & 2.6 & $-1.7-7.3$ & $-1.1-7.7-6.0$ & -0.10 & $-5.5-5.8$ \\
\hline C-reactive protein & 5.9 & $-3.2-16$ & $-0.40-14-15$ & -5.6 & $-16-6.1$ \\
\hline $\lg G$ & 13 & $6.9-20$ & $9.7 \quad 0.3-20$ & 6.1 & $-1.5-14$ \\
\hline $\lg A$ & -1.2 & $-12-11$ & $-17 \quad-31--0.70$ & -3.5 & $-17-12$ \\
\hline $\lg M$ & 8.1 & $-4.3-22$ & $-4.7 \quad-21-16$ & 3.4 & $-12-21$ \\
\hline $\lg \mathrm{E}$ & 42 & 3.3-95 & $-50-38$ & 40 & $-7.5-110$ \\
\hline
\end{tabular}

a Percentage of change in the average value of the outcome in each examined group compared with the value of the controls.

${ }^{b}$ Adjusted for age, gender, atopy, and smoking.

c Boldface indicates statistically significant results $(P \geq 0.05)$.

and the immunologic markers. With respect to atopy, statistically significant effect modification was observed for total $\operatorname{IgA}$ both when all of the exposed workers were compared with the controls $(\mathrm{P}=0.003)$ and when the exposed workers were divided into the three TTCA subgroups $(\mathrm{P}=0.045)$. Furthermore, effect modification was observed for total $\mathrm{IgG}$ when all of the exposed workers were compared with the controls $(\mathrm{P}=0.046)$, but not when the exposed workers were divided into the three TTCA subgroups $(\mathrm{P}=0.24)$. In addition, effect modification was observed for neutrophils when the exposed workers were divided into the TTCA subgroups $(\mathrm{P}=0.033)$, but not when all of the exposed workers were compared with the controls $(\mathrm{P}=0.71)$.
Different curing methods were associated with different derangements of the levels of the examined immunologic markers when the exposed workers were compared with the controls (table 6). Statistically significant changes were observed regarding total $\mathrm{IgG}$, total $\operatorname{IgE}$, and total $\operatorname{IgA}$.

We observed no statistically significant effect modification of smoking on the association between curing method and the immunologic markers. With respect to atopy, statistically significant effect modification was observed for total $\operatorname{IgA}(\mathrm{P}=0.024)$.

\section{Effects of adjustment and ethnicity}

There was a high consistency between the adjusted and unadjusted results (data not shown). When the exposed workers from Eastern Asia were excluded, the pattern was consistent with the results from the whole study population (data not shown).

\section{Discussion}

This study demonstrates an increased risk of symptoms of the eyes and airways, as well as of nausea and headache, among contemporary Swedish vulcanization workers. In addition, an immunologic response in these workers was suggested. There was no clear evidence of effect modification for either smoking or atopy, apart from atopy on total IgA. Furthermore, no clear dose-response relationships were found with TTCA.

The highest risks of eye, nose, and throat symptoms, as well as of hoarseness, severe dry cough, nausea and headache, were observed among the exposed workers with intermediate TTCA levels. However, these exposed workers did not have significantly more symptoms 
than the exposed workers with high TTCA levels (data not shown). [See table 3.] The pattern with the most symptomatics in the intermediate TTCA group probably reflects the possibility that the symptoms, at least in part, are caused by exposure that does not correlate with $\mathrm{CS}_{2}$. The pattern for most of the persons with symptoms belonging to the intermediate TTCA group may also be due to healthy worker selection. Nevertheless, it is not probable since eight different companies with divergent exposure levels were included in the study (7) and a healthy worker selection between the companies is unlikely. However, healthy worker selection within the companies is still possible.

There may have been information bias concerning the reporting of symptoms, both on the part of the observed workers and the observer. However, at the time of the medical examinations, the results of the biomarker analyses were not known to the workers or the investigators. Furthermore, occupational and medical histories were obtained in structured interviews strictly following a questionnaire. The same specialist performed all of the interviews. Moreover, before the physician's interviews, the participants had answered self-administered questionnaires with questions dealing with symptoms during the last year. The agreement between the questionnaire and the structured interviews showed good-to-moderate agreement regarding eye symptoms, nose symptoms, and nose bleeds (the only symptoms asked for in both the questionnaire and the structured interviews, data not shown). In our study, the information from the interviews was used instead of that from the questionnaires since it was the best alternative for obtaining a complete history without missing data, and, furthermore, the nature of the symptoms could be clarified. In conclusion, information bias appears to be of minor importance.

On the day of the medical examinations, the participants responded to questions asked by a nurse concerning symptoms during the last 3 days. When the analyses were repeated using this recording of symptoms, the pattern was similar to the recording of symptoms for the last 12 months (data not shown). Thus it may have been possible to find an association between TTCA and symptoms recorded during 12 months in our study if an association had existed even though most TTCA is excreted within 24 hours after exposure to $\mathrm{CS}_{2}(16)$.

$\mathrm{CS}_{2}$ can be formed in vivo in exposure to dithiocarbamates (17), which are used as accelerators. This $\mathrm{CS}_{2}$ is subsequently metabolized to TTCA. Thus there may be sources of urinary TTCA, apart from $\mathrm{CS}_{2}$ in vulcanization fumes, but there are indications that these exposures may be of minor importance in the rubber industry (11). Furthermore, it is known that many cruciferous vegetables, such as cauliflower, broccoli, and radish, contain endogenous TTCA, which is excreted unchanged in urine $(18,19)$. This exposure may be of minor importance as well, as the differences were large between the exposed workers and the controls in regard to TTCA.

Ethnicity may be associated with differences in exposure, different dietary intake, and the recording of symptoms, as well as genetic background. Therefore, attempts were made to identify participants with Eastern Asian descent, using their names as an indicator of ethnicity. When the presumable Eastern Asian participants were excluded, the pattern was consistent with the results for the whole study population.

An increased risk of itching, running, or burning eyes was observed among the exposed workers in our study. This finding is in agreement with that of Sparks et al (20), who observed an increased risk of burning eyes at work among other rubber workers (ie, processing and mill workers) and with that of Zuskin et al (4), who found a high prevalence of eye irritation among rubber workers in Croatia.

Fine \& Peters (1) showed an increased prevalence of chronic and acute bronchitis among vulcanization workers when they were compared with other rubber workers, and Zuskin et al (4) found a higher prevalence of chronic bronchitis among rubber workers in Croatia than among their controls. An increased risk of severe dry cough was observed in our study. Furthermore, we observed the same pattern with the highest risk among the workers with less than maximum exposure, as Fine \& Peters (1) did regarding acute bronchitis. However, Fine \& Peters (1) defined the exposure according to mass respirable particulate.

Weeks et al (5) showed an increased risk of shortness of breath, wheezing, chest tightness, cough, and sputum production among vulcanization workers when they were compared with other rubber workers. Zuskin et al (4) showed a higher prevalence of chronic cough and phlegm, dyspnea, and chest tightness among rubber workers than among their controls. In our study, however, no increased risk of dyspnea and the like was observed among the vulcanization workers when they were compared with the controls. One possibility for the diversity in the results could be that the exposure in our study was lower than in the survey of 1981 and the Croatian survey.

Weeks et al (5) did not find an increased risk of nausea and headache, which was observed in our study. One difference between the two studies is the controls. Weeks et al (5) used other rubber workers as controls, while we used participants with no occupational contact with rubber chemicals. Thus it may be that exposure giving rise to nausea and headache is not specific to the vulcanization department. In the study of Zuskin et al (4), the risk of headache was not compared between the exposed workers and the controls. 
Different vulcanization methods appear to give rise to different symptoms. For example, the risk of symptoms among the exposed workers using compression and injection vulcanization and having low TTCA levels differed from that of the exposed workers using continuous vulcanization and having higher TTCA levels. Moreover, the compression and injection method was associated with more symptoms than the other methods were. This finding further emphasizes the notion that some symptoms, in part, are associated with an exposure other than $\mathrm{CS}_{2}$. Kromhout et al (21) showed that different curing methods, as well as a difference in pressure and temperature during curing, is associated with different exposure. However, to the best of our knowledge, the differences in symptoms in relation to the exposure category have not been studied earlier, and they need to be further examined.

An immunologic response among the exposed workers was indicated by the increased concentrations of leukocytes, neutrophils, eosinophils, and total IgG. Noteworthy was the elevated levels of immunologic cells in the group with high levels of TTCA. This finding may suggest that the elevated concentrations of immunologic markers are related to $\mathrm{CS}_{2}$ exposure, or to a correlating exposure, although the symptoms could have been caused by a different exposure. The levels of total IgG were increased in all of the TTCA subgroups; this finding indicates that total IgG may be induced even as a result of low $\mathrm{CS}_{2}$ exposures. An alternative explanation is, of course, that the total $\operatorname{IgG}$ is directed against exposures that are not related to $\mathrm{CS}_{2}$ and vulcanization fumes.

The exposed workers curing with different methods differed in regard to the average level of the examined immunologic markers. Notably, exposed workers curing with hot air, microwaves, or a fluid-bed had decreased levels of total IgA, and the exposed workers curing with compression and injection had increased levels of total $\operatorname{IgE}$. The importance of these findings is not clear and should be further investigated in future studies.

Some effect modifications were found. However, the only consistent finding was the effect of atopy on the association between exposure and total IgA.

TTCA was used as an index substance of vulcanization fumes in this study. There were slight associations between this biomarker of exposure and the immunologic markers. However, there were no clear associations with the symptoms. Thus the use of one single exposure index may be insufficient, and it may be favorable to use more than one index substance to characterize exposure to rubber fumes.

The work environment in the rubber industries in Sweden has been improved during the last few decades. However, our study shows that the exposure still gives rise to significant health effects. The highest exposurerelated risks were found for nausea, nose bleeds, severe dry cough, and total IgG levels. Thus further improvements of the work environments are necessary.

\section{Acknowledgments}

We thank Eva Assarsson, Inger Bensryd, and Kerstin Diab for collecting the samples and Åsa Amilon for skillfully analyzing the TTCA concentrations. Furthermore, we thank Ulf Bergendorf for his help with the exposure assessment.

The study was supported by AFA [Swedish Labour Market Insurance Company], the Swedish Council for Working Life and Social Research, the Swedish Research Council, Skane county council's research and development foundation, and the Medical Faculty at Lund University, Sweden.

\section{References}

1. Fine LJ, Peters JM. Respiratory morbidity in rubber workers, I: prevalence of respiratory symptoms and disease in curing workers. Arch Environ Health. 1976;31(1):5-9.

2. Fine LJ, Peters JM. Respiratory morbidity in rubber workers, II: pulmonary function in curing workers. Arch Environ Health. 1976;31(1):10-4.

3. Weeks JL, Peters JM, Monson RR. Screening for occupational health hazards in the rubber industry, part I. Am J Ind Med. 1981;2(2):125-41.

4. Zuskin E, Mustajbegovic J, Schachter EN, Doko-Jelinic J, Budak A. Longitudinal study of respiratory findings in rubber workers. Am J Ind Med. 1996;30(2):171-9.

5. Weeks JL, Peters JM, Monson RR. Screening for occupational health hazards in the rubber industry, part II: health hazards in the curing department. Am J Ind Med. 1981;2(2):143-51.

6. Craig D, Davidson WL, Juve AE. Tetramethylthiuram disulfide vulcanization of extracted rubber, V: low molecular products and the mechanism of zinc oxide activation. J Polym Sci. 1951;6(2):177-187.

7. Jönsson LS, Broberg K, Bergendorf U, Axmon A, Littorin M, Jönsson BAG. Levels of 2-thiothiazolidine-4-carboxylic acid (TTCA) and effect modification of polymorphisms of glutathione-related genes in vulcanization workers in the southern Sweden rubber industries. Int Arch Occup Environ Health. In press 2007.

8. DeCaprio AP, Spink DC, Chen X, Fowke JH, Zhu M, Bank S. Characterization of isothiocyanates, thioureas, and other lysine adduction products in carbon disulfide-treated peptides and protein. Chem Res Toxicol. 1992;5(4):496-504.

9. Karol MH, Macina OT, Cunningham A. Cell and molecular biology of chemical allergy. Ann Allergy Asthma Immunol. 2001;87(6, suppl 3):28-32.

10. Cox C, Hee SS, Tolos WP. Biological monitoring of workers exposed to carbon disulfide. Am J Ind Med. 1998;33(1):4854. 
11. Vermeulen R, Jönsson BAG, Lindh CH, Kromhout H. Biological monitoring of carbon disulphide and phthalate exposure in the contemporary rubber industry. Int Arch Occup Environ Health. 2005;78(8):663-9.

12. Nielsen J, Welinder H, Schütz A, Skerfving S. Specific serum antibodies against phthalic anhydride in occupationally exposed subjects. J Allergy Clin Immunol. 1988;82(1):126-33.

13. Littorin M, Rylander L, Skarping G, Dalene M, Welinder H, Strömberg U, et al. Exposure biomarkers and risk from gluing and heating of polyurethane: a cross sectional study of respiratory symptoms. Occup Environ Med. 2000;57(6):396-405.

14. Mazzachi BC, Peake MJ, Ehrhardt V. Reference range and method comparison studies for enzymatic and Jaffe creatinine assays in plasma and serum and early morning urine. Clin Lab. 2000;46(1-2):53-5.

15. Vittinghoff E, Shiboski SC, Glidden DV, McCulloch CE. Regression methods in biostatistics: linear, logistic, survival and repeated measures models. New York (NY): Springer; 2005.

16. Riihimäki V, Kivistö H, Peltonen K, Helpiö E, Aitio A. Assessment of exposure to carbon disulfide in viscose production workers from urinary 2-thiothiazolidine-4-carboxylic acid determinations. Am J Ind Med. 1992;22(1):85-97.

17. Johnson DJ, Graham DG, Amarnath V, Amarnath K, Valentine WM. The measurement of 2-thiothiazolidine-4-carboxylic acid as an index of the in vivo release of CS2 by dithiocarbamates. Chem Res Toxicol. 1996;9(5):910-6.

18. Simon P, Nicot T, Dieudonne M. Dietary habits, a non-negligible source of 2-thiothiazolidine-4-carboxylic acid and possible overestimation of carbon disulfide exposure. Int Arch Occup Environ Health. 1994;66(2):85-90.

19. Kivistö H. TTCA measurements in biomonitoring of low-level exposure to carbon disulphide. Int Arch Occup Environ Health. 2000;73(4):263-9.

20. Sparks PJ, Smith TJ, Fine LJ, Treitman RD, Spiegelman DL. Respiratory morbidity among processing and mill workers: a cross-sectional survey in three tire-manufacturing plants. J Occup Med. 1982;24(9):690-5.

21. Kromhout H, Swuste P, Boleij JS. Empirical modelling of chemical exposure in the rubber-manufacturing industry. Ann Occup Hyg. 1994;38(1):3-22.

Received for publication: 20 October 2006 